\title{
Comparative radiographic features of community acquired legionnaires' disease, pneumococcal pneumonia, mycoplasma pneumonia, and psittacosis
}

\author{
JT MACFARLANE, AC MILLER, WH RODERICK SMITH, AH MORRIS, DH ROSE
}

From the Departments of Thoracic Medicine and Radiology, City Hospital, Nottingham

ABSTRACT The features of the chest radiographs of 49 adults with legionnaires' disease were compared with those of 91 adults with pneumococcal pneumonia (31 of whom had bacteraemia or antigenaemia), 46 with mycoplasma pneumonia, and 10 with psittacosis pneumonia. No distinctive pattern was seen for any group. Homogeneous shadowing was more frequent in legionnaires' disease $(40 / 49$ cases) $(\mathrm{p}<0.005)$, bacteraemic pneumococcal pneumonia $(25 / 31)$ $(\mathrm{p}<0.01)$ and non-bacteraemic pneumococcal pneumonia $(42 / 60)(\mathrm{p}<0.05)$ than in mycoplasma pneumonia (23/46). Multilobe disease at presentation was commoner in bacteraemic pneumococcal pneumonia $(20 / 31)$ than in non-bacteraemic pneumococcal pneumonia $(15 / 60)$ $(p<0.001)$ or legionnaires' disease $(19 / 49) \quad(p<0.025)$. In bacteraemic pneumococcal pneumonia multilobe disease at presentation was associated with increased mortality. Pleural effusions and some degree of lung collapse were seen in all groups, although effusions were commoner in bacteraemic pneumococcal pneumonia. Cavitation was unusual. Lymphadenopathy occurred only in mycoplasma pneumonia (10/46). Radiographic deterioration was particularly a feature of legionnaires' disease (30/46) and bacteraemic pneumococcal pneumonia (14/27), and these groups also showed slow radiographic resolution in survivors. Radiographic resolution was fastest with mycoplasma pneumonia; psittacosis and non-bacteraemic pneumococcal pneumonia cleared at an intermediate rate. Residual intrapulmonary streaky opacities remained in over a quarter of survivors from legionnaires' disease (12/42) and bacteraemic pneumococcal pneumonia (5/19).

Recent studies of community acquired pneumonia in Britain have re-emphasised the importance of pneumococcal infection and have also identified legionnaires' disease, Mycoplasma pneumoniae infection, and psittacosis as not infrequent causes of pneumonia. ${ }^{2}$

Although there have been several reports ${ }^{3-10}$ on the radiographic features of individual types of pneumonia which have emphasised specific patterns there have been few studies which have looked at comparative radiographic features of these common pneumonias. It has been suggested ${ }^{11} 12$ that some pneumonias, in particular legionnaires' disease, have certain clinical features that may aid early diagnosis. We were interested to see whether similar help could be obtained from the chest radiographs

Address for correspondence: Dr JT Macfarlane, Department of Thoracic Medicine, City Hospital, Nottingham NG5 1PB.

Accepted 27 September 1983 of patients with pneumonia.

We have therefore reviewed the chest radiographs of 196 adults with common types of community acquired pneumonia.

\section{Methods}

The chest radiographs of 49 consecutive adults admitted to hospital with community acquired legionnaires' disease were compared with the chest radiographs of 91 adults with pneumococcal pneumonia (31 of whom had pneumococcal bacteraemia or antigenaemia or both), 46 with $\mathrm{Myco}$ plasma pneumoniae pneumonia, and 10 with Chlamydia psittaci (psittacosis) pneumonia. (In the rest of the paper "bacteraemic" is used as shorthand for "with bacteraemia or antigenaemia or both.") Most cases (66\%) were studied prospectively.

Legionnaires' disease was diagnosed serologically $\mathbb{D}$ by the indirect fluorescent antibody test in 44 cases 
and by the detection of the organism in lung or respiratory secretions by culture or by direct fluorescent antibody staining in five cases. $L$ pneumophila serogroup 1 infection was identified in 46 cases, $L$ micdadei in two cases, and $L$ bozemanii in one case. Mycoplasma pneumonia and psittacosis were diagnosed serologically by the complement fixation test. A fourfold rise in antibody titre or an unchanging titre of more than 1/256 were accepted as evidence of infection in cases diagnosed serologically. Pneumococcal infection was diagnosed by the culture of Streptococcus pneumoniae from blood, pleural fluid, or lung and/or the detection of pneumococcal polysaccharide capsular antigen in serum, urine, sputum, pleural fluid, or lung by countercurrent immunoelectrophoresis.

Radiographs were reviewed systematically by two observers, at least one of whom was unaware of the cause or outcome of the pneumonia. In addition to posteroanterior views, lateral views were available in most instances. Shadowing was recorded as mainly homogeneous or mainly patchy. Other features, including pleural fluid, lobar or segmental collapse (loss of volume), hilar lymphadenopathy and cavitation, were noted.

To assess the rate of radiographic recovery, serial chest radiographs, taken at roughly monthly intervals until shadowing had resolved, were examined for $93 \%$ of survivors (161 cases).

Statistical analysis was performed with the $\chi^{2}$ test with Yates's correction for small numbers where appropriate.

\section{Results}

The details of the cases studied are shown in table 1 . At presentation half of the 46 patients with mycoplasma pneumonia and $6 / 10(60 \%)$ of those with psittacosis had homogeneous radiographic shadowing. Homogeneous shadowing was significantly commoner in the bacterial groups than in those with mycoplasma pneumonia, being present in 40/49 $(82 \%)$ patients with legionnaires' disease $(\mathrm{p}<$ $0 \cdot 005), 25 / 31(81 \%)$ with bacteraemic pneumococcal pneumonia $(p<0.01)$, and $42 / 60(70 \%)$ with non-bacteraemic pneumococcal pneumonia $(p<$ $0 \cdot 05)$. A predilection was seen for the lower lobes in all groups.

The extent of radiographic shadowing on presentation is shown in table 2 . Multilobe disease was significantly commoner in bacteraemic pneumococ-

Table 1 Details of cases studied

\begin{tabular}{|c|c|c|c|}
\hline & $\begin{array}{l}\text { No of } \\
\text { patients }\end{array}$ & $\begin{array}{l}\text { Mean age } \\
\text { (y) } \\
\text { (range) }\end{array}$ & $\begin{array}{l}\text { No (\%) } \\
\text { of deaths }\end{array}$ \\
\hline Legionnaires' disease & 49 & \multirow{5}{*}{$\begin{array}{l}51 \\
(25-77) \\
61 \\
(24-78) \\
47 \\
(13-79) \\
30 \\
(10-63) \\
46 \\
(16-75)\end{array}$} & $6(12)$ \\
\hline $\begin{array}{l}\text { Bacteraemic/antigenaemic } \\
\text { pneumococcal pneumonia }\end{array}$ & 31 & & $10(32)$ \\
\hline $\begin{array}{l}\text { Non-bacteraemic/antigenaemic } \\
\text { pneumococcal pneumonia }\end{array}$ & 60 & & $7(12)$ \\
\hline Mycoplasma pneumonia & 46 & & 0 \\
\hline Psittacosis & 10 & & 0 \\
\hline
\end{tabular}

Table 2 Extent of radiographic shadowing on presentation (number of fatal cases in square brackets)

\begin{tabular}{|c|c|c|c|}
\hline & No of patients & No (\%) with one lobe affected & No (\%) with two or more lobes affected \\
\hline $\begin{array}{l}\text { Legionnaires' disease } \\
\text { Bacteraemic/antigenaemic }\end{array}$ & 49 & $30(61) \dagger[2]$ & $19(39)[4]$ \\
\hline $\begin{array}{l}\text { pneumococcal pneumonia } \\
\text { Non-bacteraemic/antigenaemic }\end{array}$ & 31 & $11(35)^{*} \dagger[1] \ddagger$ & $20(65)[9] \ddagger$ \\
\hline $\begin{array}{l}\text { pneumococcal pneumonia } \\
\text { Mycoplasma pneumonia } \\
\text { Psittacosis }\end{array}$ & $\begin{array}{l}60 \\
46 \\
10\end{array}$ & $\begin{array}{r}45(75)^{*}[5] \\
22(48)[0] \\
6(60)[0]\end{array}$ & 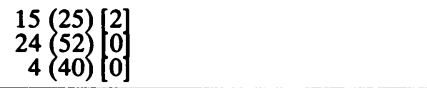 \\
\hline
\end{tabular}

Groups sharing a symbol have significantly different numbers of cases: ${ }^{*} p<0.001 ; \nmid p<0.025 ; \ddagger p<0.05$.

Table 3 Number and percentage of patients in each group showing associated radiographic features

\begin{tabular}{|c|c|c|c|c|c|}
\hline & \multirow{2}{*}{$\begin{array}{l}\text { No of } \\
\text { patients }\end{array}$} & \multicolumn{4}{|c|}{ No (\%) of patients with } \\
\hline & & pleural fuid* & pulmonary collapse & lymphadenopathy & lung cavitation \\
\hline $\begin{array}{l}\text { Legionnaires' disease } \\
\text { Bacteraemic/antigenaemic }\end{array}$ & 49 & $12(24)[0]$ & $18(37)$ & 0 & $1(2)$ \\
\hline $\begin{array}{l}\text { pneumococcal pneumonia } \\
\text { Non-bacteraemic/antigenaemic }\end{array}$ & 31 & $16(52) \dagger[2]$ & $8(26)$ & 0 & $2(6)$ \\
\hline $\begin{array}{l}\text { pneumococcal pneumonia } \\
\text { Mycoplasma pneumonia } \\
\text { Psittacosis }\end{array}$ & $\begin{array}{l}60 \\
46 \\
10\end{array}$ & $\left.\begin{array}{r}14(23) \\
9 \\
2(20) \\
20)\end{array}\right]\left[\begin{array}{l}4 \\
4 \\
0\end{array}\right]$ & $\begin{array}{r}15(25) \\
12(26) \\
2(20)\end{array}$ & $\begin{array}{r}0 \\
10\end{array}$ & $\begin{array}{l}2(3) \\
0 \\
1(10)\end{array}$ \\
\hline
\end{tabular}

†Significant difference $(\mathrm{p}<0.025)$ from other groups with the exception of patients with psittacosis.

*Numbers in square brackets indicate numbers of cases where pleural fluid occupied at least one third of hemithorax. 
cal pneumonia than in the other pneumococcal pneumonias $(p<0.001)$ or in legionnaires' disease $(p<0.025)$. The mortality rate was higher in patients with bacteraemic pneumococcal pneumonia who had multilobe disease than in those with disease confined to one lobe at presentation $(p<0.05)$. Associated radiographic features that were noted are shown in table 3. Pleural fluid was detected more often $(p<0.025)$ in bacteraemic pneumococcal pneumonia than in the other groups, with the exception of patients with psittacosis. Swollen lobes causing bulging fissures were seen in three cases (one each of pneumococcal, mycoplasma, and psittacosis pneumonia).

Deterioration apparent from chest radiographs repeated after admission was commoner in legionnaires' disease $(30 / 46$ cases $(65 \%), p<0.005)$ and bacteraemic pneumococcal pneumonia $(14 / 27$ $(52 \%), p<0.025)$ than in non-bacteraemic pneumococcal pneumonia $(15 / 57(26 \%)$ or in mycoplasma pneumonia (11/44 (25\%)). No patients with psittacosis showed radiographic deterioration. Some of the patterns of radiographic deterioration are shown in table 4. An increase in pleural fluid and pulmonary collapse was also seen in some cases. Spread of shadowing within the same lung and also to the previously unaffected opposite lung was par- ticularly a feature of legionnaires' disease and bacteraemic pneumococcal pneumonia.

The rate of radiographic resolution for each group is shown in the figure. Pulmonary shadowing cleared particularly slowly after legionnaires' disease and bacteraemic pneumococcal pneumonia. The clearance of pulmonary shadows was significantly faster with mycoplasma pneumonia than with legionnaires' disease $(\mathrm{p}<0.001)$ or pneumococcal pneumonia with or without bacteraemia $(p<0.01$ and $p<0.05$ respectively) at four weeks, or with legionnaires' disease $(p<0.001)$ or bacteraemic pneumococcal pneumonia $(p<0.01)$ at eight and at 12 weeks. The difference in rates of clearance for pneumococcal pneumonia with and without bacteraemia was significant only at eight weeks $(p<0.01)$. The rate of clearance was significantly faster in bacteraemic pneumococcal pneumonia than in legionnaires' disease at eight weeks $(p<0.001)$ and 12 weeks $(p<$ 0.025 ).

After resolution of pulmonary shadows residual intrapulmonary linear streaky opacities were still present in over a quarter of patients with legionnaires' disease and bacteraemic pneumococcal pneumonia (table 5). Residual pleural shadows were noted in a third of the latter group but were uncommon in the other groups (table 5).

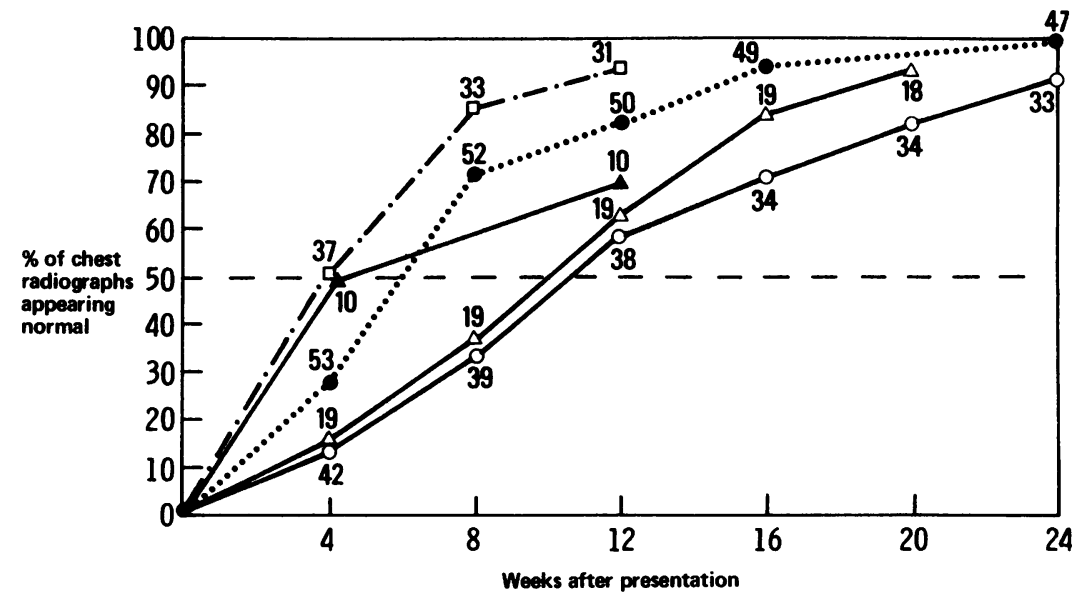

Percentages of surviving patients showing radiographic clearance at four weekly intervals after admission to hospital. Numbers by lines indicate the numbers of patients for whom data were available at those points.

$\bigcirc \_\triangle$ Legionnaires' disease $(n=42) ; \triangle \longrightarrow$ bacteraemic or antigenaemic pneumococcal pneumonia $(n=19)$; -... other pneumococcal pneumonias $(n=53) ; \square-\ldots-\square$ mycoplasma pneumonia $(n=37) ; \Delta-\Delta$ psittacosis pneumonia $(n=10)$. 
Table 4 Patterns of deterioration on chest radiographs taken after presentation

\begin{tabular}{|c|c|c|c|c|}
\hline & \multirow[t]{2}{*}{ No of patients } & \multicolumn{3}{|c|}{ No (\%) of patients with } \\
\hline & & spread in same lobe & $\begin{array}{l}\text { spread to other lobes } \\
\text { of same lung }\end{array}$ & $\begin{array}{l}\text { spread to } \\
\text { opposite lung }\end{array}$ \\
\hline $\begin{array}{l}\text { Legionnaires' disease } \\
\text { Bacteraemic/antigenaemic }\end{array}$ & 46 & $20(43)$ & $12(26)$ & $13(28)$ \\
\hline $\begin{array}{l}\text { pneumococcal pneumonia } \\
\text { Non-bacteraemic/antigenaemic }\end{array}$ & 27 & $6(22)$ & $6(22)$ & $6(22)$ \\
\hline $\begin{array}{l}\text { pneumococcal pneumonia } \\
\text { Mycoplasma pneumonia } \\
\text { Psittacosis }\end{array}$ & $\begin{array}{l}57 \\
44 \\
10\end{array}$ & $\begin{array}{l}6(10) \\
3(7) \\
0\end{array}$ & $\begin{array}{ll}5 & (9) \\
3 & (7) \\
0 & \end{array}$ & $\begin{array}{ll}5 & (9) \\
1 & (2) \\
0 & \end{array}$ \\
\hline
\end{tabular}

More than one pattern was present in some patients, and increasing pleural fluid or pulmonary collapse was noted in some cases.

\section{Discussion}

The radiographic pattern on admission to hospital was not particularly helpful in differentiating types of pneumonia. Homogeneous lobar or segmental shadows were commoner than patchy shadows in the bacterial groups, but were also seen in half of the patients with mycoplasma pneumonia. A study of 60 adults with mycoplasma pneumonia in Bristol also showed that homogeneous and patchy shadows were found with equal frequency. ${ }^{10}$ Attempts to differentiate the type of pneumonia from "characteristic" radiographic changes are likely to be unsuccessful. In one study a panel of six radiologists assessed initial radiographs from 31 patients with pneumonia. ${ }^{13}$ Diagnosis of bacterial pneumonia was correct in two thirds of cases, but $81 \%$ of cases of mycoplasma pneumonia were diagnosed as bacterial.

The lower lobes were affected most commonly and this seems to be true for any type of pneumonia.. ${ }^{610}$ Multilobe disease at presentation was commoner in pneumococcal pneumonia with bacteraemia. Probably in patients with multilobe disease pneumococci are more likely to be spilled into the bloodstream, causing bacteraemia. We found a significant association between multilobe disease and mortality for bacteraemic pneumococcal pneumonia. Similarly Heffron in $1939^{14}$ noted a direct relationship between mortality in pneumococcal pneumonia and the number of lobes affected. These findings may reflect a relationship between the number of lobes affected, the amount of bacteraemia, and mortality.

Appreciable pleural effusions were commoner in bacteraemic pneumococcal pneumonia but were also present in $20-24 \%$ of the other groups. Effusions might have been diagnosed more often if we had used lateral decubitus radiographs, as one study using this technique reported pleural fluid in nearly $60 \%$ of patients with pneumococcal pneumonia. ${ }^{\text {is }}$ Effusions were small in our patients with legionnaires' disease and this has been the experience of others. ${ }^{3}$ The presence of large effusions in four patients with mycoplasma pneumonia was surprising. Although effusions have been reported in from $8 \%^{10}$ to $14 \%$ of cases the effusions have usually been very small. In one of our patients mycoplasma pneumonia was considered only when cold agglutinins were discovered in pleural fluid removed from a large effusion.

Some degree of pulmonary collapse was seen in over a quarter of patients. In one patient there was complete collapse of the lung, due to a sputum plug that was later removed bronchoscopically. Thus, although pulmonary collapse can be due to considerable endobronchial obstruction (by a neoplasm or foreign body, for example), it also occurs commonly in otherwise uncomplicated pneumonias.

A swollen lobe has been regarded as a feature suggestive of klebsiella pneumonia but this may be misleading, ${ }^{16}$ as we also noted. The swollen lobe probably represents only an intense inflammatory

Table 5 Residual abnormalities noted on chest radiographs in survivors

\begin{tabular}{llll}
\hline & $\begin{array}{l}\text { No of } \\
\text { survivors }\end{array}$ & \multicolumn{1}{l}{ No (\%) with } \\
\cline { 2 - 4 } & & $\begin{array}{l}\text { intrapulmonary linear } \\
\text { streaky opacities }\end{array}$ & pleural shadows \\
\hline Legionnaires' disease & 42 & $12(29)$ & $3(7)$ \\
Bacteraemic/antigenaemic pneumococcal pneumonia & 19 & $5(26)$ & $7(37)$ \\
Non-bacteraemic/antigenaemic pneumococcal pneumonia & 53 & $5(9)$ & $(9)$ \\
Mycoplasma pneumonia* & 37 & 0 & 1 \\
Psittacosis & 10 & $1(10)$ & $2(20)$ \\
\hline
\end{tabular}

*Persisting hilar lymphadenopathy was noted in one case. 
exudative response to any severe infection.

Hilar lymphadenopathy was identified only in mycoplasma pneumonia $(22 \%)$, which might make it a useful point for differential diagnosis. Similarly, Brolin and Wernstedt ${ }^{9}$ found lymphadenopathy in $22 \%$ of cases of mycoplasma pneumonia. Hilar lymphadenopathy has also been reported in psittacosis ${ }^{7}$ and was at one time a feature of resolving pneumococcal pneumonia in patients treated symptomatically, ${ }^{17}$ although it is not seen now that antibiotics are used. Routine conventional or computed hilar tomography might have given more information about the frequency and distribution of lymphadenopathy in our groups.

Lung cavitation was unusual in all the types of pneumonia studied. Cavitation was seen in only one patient with L pneumophila infection and it has been noted only occasionally in other series, except in immunosuppressed patients. ${ }^{3-5}$ Cavitation has been reported previously with psittacosis, ${ }^{7}$ and is a well known feature of staphylococcal pneumonia.

Radiographic deterioration was particularly common with legionnaires' disease and bacteraemic pneumococcal pneumonia. The propensity of legionnaires' disease to spread has been recorded before, although spread is said to be unusual in other pneumonias. ${ }^{518}$ Radiographic deterioration was also a feature of mycoplasma pneumonia. This can be regardless of whether effective antibiotics are used, as Borthwick et $a^{8}$ found progression in $20 \%$ of patients who were being treated appropriately.

The reason why radiographic shadows often spread in legionnaires' disease, despite erythromycin treatment, ${ }^{3}$ is not clear but may be related to the pathogenesis of legionnaires' disease pneumonia. $L$ pneumophila is a facultative intracellular pathogen that enters and multiplies in alveolar macrophages, where it is relatively inaccessible to antibiotics. Interestingly, Baskerville et al (paper presented to Second International Symposium on Legionella, Atlanta, 1983) noted that guineapigs infected with legionellae by aerosol and then treated with either erythromycin or rifampicin behaved in very different ways. Only rifampicin was effective in clearing the lung of legionellae rapidly and reducing pathological changes. This may reflect the better penetration of infected macrophages by rifampicin than by erythromycin. There are, however, no data on radiographic clearance after rifampicin treatment.

The rate of radiographic resolution was principally related to the cause of the pneumonia. Clearance was faster in mycoplasma pneumonia than in legionnaires' disease or pneumococcal pneumonia and $90 \%$ of patients had a normal radiograph within two months. Finnegan et al ${ }^{10}$ found a similar resolu- tion rate for mycoplasma pneumonia, $40 \%$ of radiographs being clear by four weeks and $96 \%$ by eight weeks. The clearance of shadows after psittacosis is somewhat slower than after mycoplasma pneumonia. ${ }^{19}$

Legionnaires' disease and bacteraemic pneumococcal pneumonia cleared more slowly than other pneumonias. Jay et $a^{6}$ followed 72 survivors of bacteraemic pneumococcal pneumonia and found that all the radiographs had cleared by four months. Clearance in pneumococcal pneumonia took over five months in our study, and at that stage only $80 \%$ of the patients with legionnaires' disease had shown radiographic resolution. Slow radiographic resolution after legionnaires' disease has been noted before. ${ }^{45}$ In only one series has fairly rapid clearance of radiographic shadowing been reported after legionnaires' disease. Kirby $e^{2} a^{3}$ found radiographic resolution in three-quarters of 21 survivors of legionnaires' disease after two months. These patients were, however, diagnosed early during an outbreak of hospital legionnaires' disease, and all except two received treatment with erythromycin. The reason for the slow radiographic resolution in legionnaires' disease is not clear. The presence of linear shadows on radiographs in 12 of our patients with legionnaires' disease after resolution of pulmonary consolidation suggests that there may be slow fibrosis or persisting atelectasis on recovery. Others have commented on these residual abnormalities. ${ }^{5}$ Pathological studies in animals support the view that lung fibrosis is common after legionnaires' disease pneumonia. (Baskerville et al, paper presented to Second International Symposium on Legionella, Atlanta, 1983). The rate of resolution is also affected by increasing age, alcoholism, and underlying chronic lung disease. ${ }^{6}$

We conclude that there are no unique radiographic features of different types of community acquired pneumonia, but that patients with legionnaires' disease and bacteraemic pneumococcal pneumonia often show radiographic deterioration after presentation and the survivors delayed resolution.

We are most grateful to Dr Tony Arnold for help with collecting the chest radiographs.

\section{References}

${ }^{1}$ Macfarlane JT, Finch RG, Ward MJ, Macrae AD. Hospital study of adult community acquired pneumonia. Lancet 1982;ii:255-8.

${ }^{2}$ White RJ, Blainey AD, Harrison KJ, Clarke SKR. Causes of pneumonia presenting to a district general hospital. Thorax 1981;36:566-70. 
${ }^{3}$ Kirby BD, Peck H, Meyer RD. Radiographic features of legionnaires' disease. Chest 1979;76:562-5.

${ }^{4}$ Dietrich PA, Johnson RD, Fairbank JT, Walke JS. The chest radiograph in legionnaires' disease. Radiology 1978;127:577-82.

${ }^{5}$ Fairbank JT, Mamourian AC, Dietrich PA, Girod JC. The chest radiograph in legionnaires' disease. Radiology 1983;147:33-4.

- Jay SJ, Johanson WG, Pierce AK. The radiographic resolution of Streptococcus pneumoniae pneumonia. $N$ Engl J Med 1975;293:798-801.

${ }^{7}$ Stenström R, Jansson E, Wager O. Ornithosis pneumonia with special reference to roentgenological lung findings. Acta Med Scand 1962;171:349-56.

${ }^{8}$ Borthwich RC, Cameron DC, Philp T. Radiographic patterns of pulmonary involvement in acute mycoplasmal infection. Scand J Respir Dis 1978;59:190-3.

${ }^{9}$ Brolin I, Wernstedt L. Radiographic appearance of mycoplasmal pneumonia. Scand $J$ Respir Dis 1978;59:178-9.

${ }^{10}$ Finnegan OC, Fowles SJ, White RJ. Radiographic appearances of mycoplasma pneumonia. Thorax $1981 ; 36: 469-72$.

"Miller AC. Early clinical differentiation between legion- naires' disease and other sporadic pneumonias. Ann Intern Med 1979;90:526-9.

12 Kennedy DH, Borland W. How common is legionnaires' disease? Lancet 1983; i:360-1.

${ }^{13}$ Tew J, Calenoff L, Berlin BS. Bacterial or non bacterial pneumonia. Accuracy of radiographic diagnosis. Radiology 1977;124:607-12.

${ }^{14}$ Heffron R. Pneumonia with special reference to pneumococcus lobar pneumonia. Cambridge, USA: Harvard University Press, 1939 (reprinted 1979).

15 Taryle DA, Potts DE, Sahn SA. The incidence and clinical correlates of parapneumonic effusions in pneumococcal pneumonia. Chest 1978;74:170-3.

${ }^{16}$ Scanlon GT, Unger JD. The radiology of bacterial and viral pneumonias. Radiol Clin North Am 1973;11:317-38.

${ }^{17}$ Davies DT, Hodgson HR, Whitby LEH. The radiology of pneumonia. Lancet 1935; i:919-24.

${ }^{18}$ Helms CM, Vines JP, Sturm, et al. Comparative features of pneumococcal, mycoplasmal and legionnaires' disease. Ann Intern Med 1979;90:543-7.

19 Macfarlane JT, Macrae AD. Psittacosis. Br Med Bull 1983;39:163-7. 